This is an Accepted Manuscript of an article published by Taylor \& Francis in Journal of Nonprofit \& Public Sector Marketing on 15/05/2020 available online: https://www.tandfonline.com/doi/full/10.1080/10495142.2020.1760996 


\title{
'Everyone should muck in': a qualitative study of parkrun volunteering and conflicting motivations
}

\author{
Dr. Rachel Hallett, ORCiD 0000-0002-2238-7467 \\ Dr. Karolina Gombert, ORCiD 0000-0002-6573-0966
}

Prof. Michael Hurley, ORCiD 0000-0001-6106-2895

Centre for Health and Social Care Research, Joint Faculty of Kingston University and St. George's University of London, London, UK

Correspondence: Rachel Hallett, FHSCE, Kingston University and St. George's, University of London, Floor 6, Hunter Wing, Cranmer Terrace, London SW17 0RE.

r.hallett@sgul.kingston.ac.uk

\section{Abstract}

This study looks at volunteering at parkrun, a weekly $5 \mathrm{k}$ run/walk event held at almost 2,000 different locations worldwide, which relies on volunteers. Despite large numbers of parkrunners, and an ethos encouraging occasional volunteering, some parkrunners do not volunteer which can lead to recruitment difficulties for events. Ten parkrunners were interviewed about volunteering to explore why there might be reluctance. Data were transcribed and analysed using thematic analysis, and three interlinked themes found: becoming "hooked" on parkrun, "obligation to give back", and "reluctance to miss a run". Conflict between obligation and a desire to run or walk led to strategic volunteering to facilitate both, despite this approach potentially challenging event delivery by leaving nonrun/walk roles uncovered. Findings indicate a complex and somewhat conflicting system of preference, intrapersonal and structural constraints, mutual aid and social exchange. Gamification and the triggering of reward mechanisms may be increasing motivation to run rather than volunteer.

Keywords: sport, social exchange, mutual aid, running, community, leisure constraints 
Since its first event in 2004, as an informal 5k time-trial for 13 runners near London in the UK, "parkrun" (lower-case p) has become global. Free weekly 5k run/walk parkrun events are now held every Saturday morning at almost 2,000 locations worldwide, and over 5 million people have registered to take part (parkrun, 2019). The parkrun model through which events are delivered is widely recognised as providing community health and wellbeing benefits (Grunseit, Richards, \& Merom, 2017; Stevinson \& Hickson, 2014). Furthermore, the UK government sees the relatively low-cost, straightforward framework as offering wider potential for event development within UK health policy (Department for Culture Media and Sport, 2015).

As with many community-based events, volunteering is central to parkrun's delivery; local events are run by a small core team of regular volunteers, with parkrunners encouraged to volunteer themselves from time to time to ensure each event's sustainability. The model seems particularly relevant to contemporary sport and volunteering engagement, which has become increasingly individualised and short-term (Harris, Nichols, \& Taylor, 2017). However, like many events and organisations, volunteer recruitment can sometimes present difficulties despite expectations of reciprocity. Consequently, parkrun provides a useful case study of why people do - or perhaps more importantly do not - volunteer. This study aimed to investigate motivations and constraints, and to understand parkrunners' perceptions of parkrun events and volunteering.

\section{Volunteering: definition and theoretical context}

The UN defines volunteering as reflecting three key principles: free will, public benefit, and no direct motivation from financial reward (United Nations General Assembly, 2002). More widely, 
perception of whether an activity is volunteering is related to perceived costs and benefits, and this has been found across different cultures (Handy et al., 2000). The balance of reciprocal elements is, however, sensitive to individual differences and context (Freitag \& Manatschal, 2014). Engagement with volunteering has been found to be stronger among individuals with other-oriented motives, while those with self-oriented motives are less satisfied and less inclined to continue volunteering (Stukas, Hoye, Nicholson, Brown, \& Aisbett, 2016).

The complexity of volunteering motivation has led to various theories and research studies to try and understand better the motivation surrounding volunteering. Social Exchange Theory (SET), which was originally developed in the 1950s, suggests that individuals base their activities on achieving a balance of contribution and return (Emerson, 1976). Emerson's critique of the theory is that it can be over-simplistic if reduced to behaviourism and the assumption of rationality, but that its principles are nevertheless useful for exploring behaviour in large social networks. In practice, there are other factors in play; for example altruistic surplus theory (AST: Cunningham, 1996) describes situations where individuals focus on group benefits rather than their own. Although its application has largely been focused within the fields of urban planning and tourism, Waitt (2003) draws on AST in his study of sports volunteering and tourism at the Sydney Olympics. He focuses on the mainly economic costs and benefits (higher taxes balancing tourist spend and new facilities) and notes that patriotism may be a motivating factor. With parkrun, the main cost for volunteers is time, but the same benefit of a community facility may also be motivated by a sense of group and/or community identity - with similarities to patriotism - through wishing to be associated with parkrun and its ethos, or links with sports groups. This in turn may lead to, for example, wanting their community to benefit from a parkrun despite not 
wishing to run/walk in the event. Nevertheless, this may still have a reciprocal element in that there is an expectation of something in return even if this is for the community rather than the individual (Paraskevaidis \& Andriotis, 2017), and involvement as a volunteer may confer benefits such as social connectedness and status.

Social exchange and altruistic surplus relate to an altruism-egoism continuum proposed by Hustinx, Cnaan and Handy (2010), whereby individuals have different outlooks or personalities in terms of their priorities, which go some way to explaining variation in propensity to volunteer. Similarly, decision-making may vary according to whether extrinsic motivators (where there is some kind of perceived benefit or reward for the individual) or "warm glow" altruism is prioritised (Declerck, Boone, \& Emonds, 2013). Volunteering is recognised as providing the opportunity to make friends and develop a sense of belonging (Dallimore, Davis, Eichsteller, \& Mann, 2018; Shye, 2010). It has also been found to improve wellbeing (Jenkinson et al., 2013), particularly among older volunteers (Van Willigen, 2000). However, although these benefits have been recorded among volunteers, it is not clear whether they affect motivation prior to the experience.

The more complex environment of the individual's situation (biography) and increasingly less predictable life courses in society generally are recognised in Hustinx's previous work (Hustinx \& Lammertyn, 2003), as well as being associated with a process of "radical change" in volunteering practices (Hustinx et al., 2010, p.426) . Hustinx and her colleagues present a more reflexive approach to volunteering where shared interests create a sense of belonging, but where an individual is more likely to focus on personal preferences than broader organisational aims. 
Brudney and Meijs (2009) present a finite "energy" which can be conferred on volunteer work, but such work competes with formal employment, family, home and other commitments. Additionally, the decision to volunteer may be influenced by short term "mood"; positive affect (such as from sport participation) can affect complex decision-making (Isen, 2001). This recognition of the interaction of personal, social and contextual is consistent with leisure constraints theory (originally conceptualised as barriers: Crawford \& Godbey, 1987), which presents intrapersonal, interpersonal and structural constraints affecting leisure activities. Godbey, Crawford and Shen (2010) note that there has been empirical support for these three types, although they are interlinked and generally found to correlate. A study of sports students' perceptions of volunteering (van den Berg \& Cuskelly, 2016) found that constraints were primarily structural (perceptions of the volunteering environment due to lack of information, perceived workload and time constraints) and intrapersonal (perceived lack of skills and expectation of emotional cost), with relatively little influence from interpersonal constraints.

Alongside the development of volunteering theories, human resources management (HRM) techniques have also been presented as potential aids to recruitment and retention of volunteers. Support and training alongside planning practices were found to be particularly important in a study of rugby clubs (Cuskelly, Taylor, Hoye, \& Darcy, 2006). However, as Alfes, Antunes and Shantz note (2017), volunteering does not have the same motivations and structures as paid employment, therefore transplanting HRM approaches from for-profit contexts with paid employees is often not appropriate. Instead, HRM techniques should be tailored to the situation. For example, training may be valued and welcomed by some volunteers, while others may find that it overextends their time commitment. Current trends towards microvolunteering (activities 
taking less than half an hour) and episodic volunteering (short-term, relatively informal roles: National Council of Voluntary Organisations (NCVO), n.d.) are perhaps less suited to training, with volunteers finding alternative motivations such as social interaction.

\section{Sport participation and volunteering}

Volunteering in sport contexts forms a substantial subcategory of broader volunteering activities. Roles are wide-ranging, including support for elite and community events, within educational organisations, coaching activities, and club and event administration. In England, around 95\% of volunteer hours in sport are formal - that is, within an organisation (Nichols et al., 2016). Sports participation generally is becoming more individualised, with sports such as running seeing an increase while team sport participation has stayed relatively stable (Harris et al., 2017). This is a trend first noticed in the 1990s, and has been seen across Europe. The reasons are not clear, but Harris et al. note it coincides with an increased focus on identity and appearance which may affect activity choices. Alongside this, there is increased recognition that, although personal values are relatively constant, individual traits along with social networks and environments change over time and interact in different ways (Nichols, Hogg, Knight, \& Storr, 2019; Nichols et al., 2016), and this may mean that regular, long-term commitments are harder to maintain. This is consistent with Hustinx and Lammertyn's focus on biographical factors and the life course (2003).

There is also an increase in what Bishop and Hoggett describe as mutual aid (Bishop \& Hoggett, 1986), where an organisation is "by some of us, for all of us" rather than "by them, for 
us" (p.41). In practice, the demarcation is more of a continuum. Bishop and Hoggett note that in mutual aid, people undertaking voluntary roles do not perceive themselves as volunteers. Typically, such groups also have strong subcultures and offer members or participants the opportunity to develop their sense of value and identity through group-related performance. Shared interests are fundamental to these groups, and parkrun shares some of these qualities.

\section{parkrun}

The parkrun organisation is heavily reliant on volunteers. On August 32019 in the UK, there were 618 events, with 157,479 runners and walkers and 13,738 volunteers. This structure is supported by just 23 paid UK staff. Events are initially set up by a core team who must raise several thousand pounds sterling for event kit (in practice, this is often supported by local councils as part of their strategy to promote community health). Equipment includes scanners, timers, position tags with barcodes and a dedicated laptop. Participants register once online centrally, generating a printable barcode that is their athlete ID for any event in the world. On completion of an event, the individual is presented with a position tag which they take, along with their personal barcode, to a volunteer with a scanner near the finish line. Individual parkruns then "merge" data from the timers and scanners to produce a list of results, which is then uploaded and processed centrally. Results are sent out by email and optional text; each email provides personal results, a link to the event's results, and a link to the individual's personal record where data for all their parkruns and volunteering is available. In addition to 
income from set-up costs, the organisation is funded by sponsorship, donations and merchandise sales. The ethos is that parkrun should always be free to take part in.

Volunteer roles at parkrun are wide-ranging and include marshals, timers, scanners and a run director. Events are largely autonomous in how they set about recruiting volunteers, typically drawing attention to the need for volunteers during pre-run briefings and encouraging runners to show appreciation for those who have volunteered that week. Social media is widely used, and some events use printed sign-up sheets on-site each Saturday. However, recruitment can occasionally involve last-minute calls to fill roster gaps.

Core teams are thoroughly trained and supported during the set-up process, and coordinate volunteer teams each week. Episodic volunteers, who usually form the majority of the volunteer team, are asked to turn up half an hour before the event. Some guidance is provided, and the core team provide overall direction and support, but there is no formal training beforehand for episodic volunteers and roles are straightforward. Most volunteer roles, such as marshalling, timing and scanning barcodes, preclude the volunteer from also participating in the event as a runner or walker. A few roles, such as setting up, sorting out position tokens after the event, and "tail-walking" allow participation (although the tail-walker must remain in last position). There is no remuneration nor are expenses covered, although after 25 occasions of volunteering, volunteers qualify for a free tee-shirt.

The mutual aid model (Bishop \& Hoggett, 1986) is close to that which parkrun aspires to: i.e. by some of us, for all of us, with the "some" varying from week to week so that "most (or ideally all) of us" provide the event at some point. The key difference from Bishop and 
Hoggett's observations is the high level of promotion of volunteering and volunteers; event web homepages have a prominent "Thanks to this week's volunteers" section where the core team and episodic volunteers are named. Promotion is, nevertheless, vital where episodic volunteering is used; Hager and Brudney (2011) note that sporadic volunteer recruitment can be very challenging due to lack of mechanisms, so parkrun events use social media and an email circulation list to draw attention to vacancies in the roster. At each event, parkrunners are encouraged to volunteer at future events during the briefing, and attention is drawn to those volunteering that week, who are applauded prior to the event. Simultaneously, it is emphasised that parkrunners are not obligated to volunteer if they do not wish to do so. Volunteering at parkrun helps foster a sense of involvement, but the reciprocity of volunteering is also evident in the support and encouragement given by parkrunners to each other (Stevinson, Wiltshire, \& Hickson, 2015). It is not clear whether making a social contribution in this way offsets a possible sense of obligation to volunteer formally at parkrun.

Compared with Bishop and Hoggett's groups, there is less commitment required from parkrunners, whether that be the organisation as a whole or a local event. There are no membership fees, and participation can be as frequent or infrequent as desired; parkrun attendance is therefore somewhat transient with weaker social bonds than at a traditional sports club (Wiltshire \& Stevinson, 2018), although parkrun's success is in part credited to lack of obligation (Hindley, 2018). There is, nevertheless, a strong parkrun subculture. The free milestone tee-shirts for 50, 100, 250 and 500 runs are keenly sought after, spelling parkrun with a capital P is an indication of an "outsider", while language emphasising that events are runs, not races, and describing first finishers rather than winners, are integral to the inclusive ethos. 


\section{Rationale}

parkrun provides a useful case study for looking at volunteering practices, including reasons not to volunteer. Its structure is heavily reliant on volunteers, its framework is scalable and it is considered a highly successful model of community sport provision. Its use of episodic volunteering and lack of obligation are very much in keeping with contemporary volunteering behaviours, while its subcultures create a clear sense of "groupness". Additionally, reciprocity is encouraged and the events have well-developed strategies to recruit for volunteering roles. Despite these strengths, rosters often have spaces close to events taking place. This research was part of a larger project instigated in response to local events sometimes struggling to recruit volunteers. Wider anecdotal evidence suggests this is not uncommon, although events have rarely been cancelled (indeed, we are aware of instances where threats of cancellation filled lastminute vacancies). This in itself is not unusual across voluntary organisations; however, further research could help clarify underpinning reasons and thus assist the development of better recruitment strategies, both at parkrun as it expands globally, and in other contexts.

The research questions are:

- What constrains volunteering at parkrun?

- What motivates volunteering at parkrun?

- How do parkrunners perceive volunteering?

- How do individuals position themselves within the context of parkrun events (i.e. volunteer-led events where reciprocity is encouraged)? 


\section{Method}

A qualitative approach was taken, using 10 semi-structured interviews, and thematic analysis following the framework of Braun and Clarke (2006). This was to try and recognise different individual perspectives and how they might contribute to volunteering behaviour in the broader parkrun framework, and also placing parkrun within the wider community. Braun and Clarke's epistemological stance involves the researcher constructing themes from data (rather than the assumption that there are themes waiting to "emerge"). They advocate smaller samples so that "diversity and nuance" is not missed. There is no aim of saturation (this would be inconsistent with the approach).

The overall aim of thematic analysis, following Braun and Clarke's approach (2006), is to identify patterns in a dataset. It involves stages of familiarisation, coding, and constructing themes using code-mapping, moving forwards and backwards through stages to ensure consistency between themes and codes. It allows both inductive and deductive approaches, and was therefore considered to be well-suited to the topic in hand. Recognition of motivation and constraints from a previous survey, and the broader theoretical and research context, meant there was a deductive element to the analysis. However, as this was a relatively underexplored area of volunteering (i.e. not volunteering despite a reciprocal context), there needed to be ample scope for inductive readings.

\section{Participants}

Participants were drawn from respondents to an online survey regarding parkrun volunteering (N $=6,749)$. Maximum variation sampling was carried out with the aim of reflecting a range of 
volunteering experiences, age and gender by reference to responses in the survey. Participants who had expressed willingness to be contacted in their survey responses were emailed and invited to take part in a half hour interview: 101 emails generated 10 acceptances. Seven of the participants had not volunteered at the time of the survey, although only one had not volunteered at the time of the interview. All participants were given a $£ 10$ voucher to thank them for taking part.

Participants were aware from information provided prior to both the survey and interviews that the aim of the research was to understand volunteering better so that difficulties recruiting volunteers could be addressed. Table 1 shows demographic information, number of occasions of volunteering, and theme frequency. All participants have been given pseudonyms to ensure anonymity. The study was approved by the Faculty Research Ethics Committee at [details removed for anonymous review] and by parkrun's Research Board, an interdisciplinary group set up to engage with researchers (https://awrcparkrunresearch.wordpress.com/), which involved submitting the research proposal to the Board for consideration prior to the research taking place. 
Table 1: Participant demographics, number of volunteering occasions, and theme frequency

\begin{tabular}{|c|c|c|c|c|c|c|}
\hline Pseudonym & Age & Gender & $\begin{array}{l}\text { Number of } \\
\text { volunteering } \\
\text { occasions at } \\
\text { survey point* }\end{array}$ & $\begin{array}{l}\text { Theme } 1 \\
\text { (Hooked) }\end{array}$ & $\begin{array}{c}\text { Theme } 2 \\
\text { (Obligation } \\
\text { to give } \\
\text { back) }\end{array}$ & $\begin{array}{c}\text { Theme } 3 \\
\text { (Reluctant } \\
\text { to miss a } \\
\text { run) }\end{array}$ \\
\hline Anita & 30 & $\mathrm{~F}$ & 30 & $\checkmark$ & $\checkmark$ & $\checkmark$ \\
\hline Tom & 50 & M & 3 & $\checkmark$ & $\checkmark$ & $\checkmark$ \\
\hline Ben & 27 & M & 0 & $\checkmark$ & $\checkmark$ & \\
\hline Ian & 69 & M & 350 & $\checkmark$ & $\checkmark$ & \\
\hline John & 52 & M & 0 & $\checkmark$ & $\checkmark$ & $\checkmark$ \\
\hline Lucy & 26 & $\mathrm{~F}$ & 0 & $\checkmark$ & $\checkmark$ & $\checkmark$ \\
\hline Margaret & 58 & $\mathrm{~F}$ & 0 & $\checkmark$ & $\checkmark$ & $\checkmark$ \\
\hline Sarah & 45 & $\mathrm{~F}$ & 0 & & $\checkmark$ & $\checkmark$ \\
\hline Nicola & 39 & $\mathrm{~F}$ & 0 & & $\checkmark$ & $\checkmark$ \\
\hline Sue & 45 & $\mathrm{~F}$ & 0 & $\checkmark$ & $\checkmark$ & $\checkmark$ \\
\hline
\end{tabular}

* All non-volunteers had volunteered since the survey with the exception of Ben, who had registered to volunteer and would be doing so in the next couple of weeks. 


\section{Data}

Participants' parkrunning background, volunteering experience, and beliefs regarding volunteering were explored using a semi-structured interview schedule (see Appendix A). Each participant was interviewed individually by telephone by Author 1, with interviews recorded on a Sony ICD-TX50 digital recorder and then transcribed for analysis by an independent academic transcription service; transcriptions were reviewed and errors corrected where evident. The ten interview recordings ranged in length from 23 to 50 minutes. Author 1 disclosed her participation and volunteering on occasion during the interviews, particularly with regard to questions from participants. Due to the semi-structured nature of the interviews, she used her knowledge of parkrun to explore concepts that the participants mentioned, which would be evident to them.

\section{Analysis}

Analysis was carried out using Braun and Clarke's thematic analysis framework (2006). A contextualist approach was used with the aim of understanding individuals' constructions of their volunteering and parkrunning experiences, while also recognising the effect of contextual influences arising from the ethos of parkrun and the wider social environment.

The analysis combined deductive and inductive approaches. The deductive element concerned the area of investigation and the impetus to understand constraints and motivations to volunteer at parkrun, thus coding and themes were focused on these concepts. Findings from the online survey indicated strong elements of egoistic attitudes to volunteering and also intentions 
to volunteer that had not been realised. Additionally, comments from the survey, particularly with regard to childcare and other commitments, provoked consideration of these factors. Within these constraints, an inductive approach was used with the researchers aiming to go beyond preconceptions and to identify codes and themes that extended previous knowledge and the indications from the survey data.

Transcriptions of the interviews were read, re-read and annotated with initial codings. Codings were collated in a mind map using Freemind software (http://freemind.sourceforge.net/wiki/index.php/Main_Page) during the analysis to group codes, moving nodes to help identify themes. For example, a "Not enjoyable" node included a need to interact with other parkrunners, a dislike of "standing there" and a sense of missing out that all appeared to relate to a reluctance to miss a run, and "Reluctance to miss a run" became a theme that fitted with codes from this and several other nodes. Frequent reference was made back to the original transcripts while the analysis was taking place to ensure themes were consistent with the data. The themes were refined, and the three themes which had been identified were defined and named. Finally, during the production of this report, further reference was made to data and themes to ensure examples were consistent and communicated the findings effectively. Stages of analysis were revisited during the process. Author 1 carried out the initial analysis, then Author 2 analysed the transcripts without knowledge of Author 1's findings. Following this, the analyses were collated and compared, developed and refined. In response to Author 2's analysis, the second theme, which had previously focused on exchange, was updated to emphasise obligation and the idea of conflict in the third theme was highlighted; overall, the analyses were largely consistent. 


\section{Findings}

Three themes were identified: "Hooked", relating to the descriptions given by participants to their enthusiasm for parkrun at the point of initial participation and desire to take part frequently; "Obligation to give back" to reflect the frequently expressed view that if one runs/walks at parkrun, one should volunteer too; and "Reluctance to miss a run", reflecting a conflict between the desire to run/walk and the onus to volunteer, the first two themes. Quotes from participants are presented with pseudonym and age.

\section{Hooked}

Eight of the ten participants' transcripts reflected this theme. They had typically developed great enthusiasm for running/walking, and enjoyed competing against themselves and trying to improve their times while feeling included in the event, whatever their performance. They described how they first ran or walked at parkrun, and as a result wanted to participate as often as they could, with the term "hooked" used by several of the participants, as with Margaret, 58, who described how "She [friend] ran round with me the first time and that was it, I was hooked really and, yes, I go most weeks now."

Underpinning reasons varied and included the regularity of being able to take part and try and improve on previous performances:

I remember texting my boyfriend at the time and saying, 'I did it in under half an hour' and I was really proud so then going again the next week and being a minute quicker got me hooked really. (Anita, 30) 
Another participant particularly valued the way parkrun is organised for smooth delivery of the event and rapid communication of results:

As soon as I saw how it operated on the day and then the email you get and then being able to look at all the results just a few hours after the race, as soon as I saw it all I was hooked on that. I thought 'I'm going to absolutely love this.' (John, 52)

Anxiety regarding taking part may have preceded participation, but appears to have been easily overcome:

I just went along one week, quite nervous with a few reservations about if it's for me or would I fit in, would I feel okay, would I be last, all that stuff that you think about. But yes, I did it. I think it was last October I did my first one and then I've been hooked ever since that first one really. (Ben, 27)

The allaying of anxiety may be due to the inclusivity experienced, and the sense of competing against oneself, but still enjoying the event even if performance has plateaued:

parkrun has given me a little bit of a kind of a boost and let's see if I can beat myself. Really encouraging about not beating myself up because I'm not getting any faster at the moment. It's a fantastically positive environment for me. I mean I look awful, I look shocking, I'm a bit overweight, but it's been 
positive I suppose. ... So I try and do parkrun as many weeks as I can in the year. (Sue, 45)

Where logistics prevented participation, participants described wanting to do parkrun more frequently, as with Nicola, 39, who had to balance attending with childcare responsibilities and stated that "I don't get to parkrun as often as I like to." Overall enthusiasm for the event was encapsulated by Ian, 69, who said "I just think it's a brilliant thing and I look forward to every Saturday morning and can't wait to get there and see everybody and get the course set up."

While the "Hooked" theme indicates the passion that quickly developed for parkrun among participants, it also shows a range of perceived benefits (for example, providing a psychological "boost", getting out and seeing people and trying to improve times). Ian rarely ran at parkrun, as he felt he had plenty of other opportunities to do so and enjoyed the organising role. Ian's enjoyment of organising and the social contact of volunteering contrasted with other participants' motivations; they indicated that improving their times was a priority at the outset of becoming involved in parkrun, and that this was part of becoming a regular runner/walker. Two participants' data did not reflect the "Hooked" theme: both had young families which prevented them attending regularly, although they were keen to run/walk when other commitments allowed them to do so.

\section{Obligation to give back}

Every participant described feeling an obligation that if they ran/walked at parkrun, they should be volunteering from time to time. The pattern reflected in the transcripts was a gradual realisation that while the participant was enjoying running/walking every week, this was being 
facilitated by volunteers, and they developed a sense of obligation to volunteer themselves. From this, there was a belief that others should be doing likewise, and this was particularly notable in the transcripts of the more experienced volunteers, although some caution should be exercised as generalisability was not the aim here. Nobody questioned the need to volunteer; Sue commented that:

I know that it's free and it completely relies on volunteers, so for me it's a bit of a responsibility if I want the thing to keep going to actually do some volunteering and giving back basically. (Sue, 45)

and this view was typical.

The urge to volunteer typically developed over time, and crystallised after having taken part in events and recognising that others were volunteering in order to facilitate this. Anita, 30, commented that "After I realised I was going to parkrun quite a lot you realise that you have to give something back," and this was echoed by Tom:

The first thing that got me into marshalling was I was approaching my tenth run I thought, 'I'm taking the mickey here because these people are standing out marshalling for me, and I'm just enjoying it every Saturday.' (Tom, 50)

Participants talked about negative emotions developing if they did not volunteer. Ben described a growing sense of embarrassment at having not volunteered, suggesting a sense of unacceptability of not volunteering: 
I think because I'd done that many runs I thought it's getting a bit embarrassing now. I felt like I should have put something back having done so many free runs, if you like, where everybody else had made it happen for me. I just thought it was time for me to have a go and put something back and do my bit really. (Ben, 27)

This sense of obligation is interesting firstly because there is no demand from parkrun to volunteer, and secondly because parkrunners are not widely aware of who has volunteered and who has not, so there is no direct judgement of the individual (it is possible to view individuals' volunteering histories, but the route through the website to do so is not obvious). This suggests that negative emotions are rooted in recognition of social exchange as a "norm" within society and judgement of oneself. There may be an element of cognitive dissonance whereby the parkrunner views themselves as part of the parkrun community but their lack of contribution conflicts with a belief in the parkrun model, where volunteering, though not compulsory, is encouraged and a necessary component for event sustainability. The alternative is embarrassment (as for Ben, above), or guilt, which John, 52, acknowledged in the comment that "If I wasn't volunteering, from time to time I would feel guilty about that."

Also noticeable was the extension from participants believing that they should volunteer, to the opinion that it is important for all parkrunners to volunteer. John and Nicola had not volunteered at the time of the survey, although they had done so prior to being interviewed: 
I think the first starting point of volunteering is to believe in the whole model anyway. If you've got a complete buy-in to what parkrun is about, then you should be more encouraged to volunteer. (John, 52)

Maybe if that would help, you know, if you do fifty runs then you do have to volunteer because I think it is, it's just that same mentality, people go every week, you know, they're the first ones to complain, aren't they, and do they do actually anything to help? (Nicola, 39)

This goes beyond recognition that one can make a difference, to a broader endorsement of the overall model and expectation that others should do likewise, and this was quantified by Tom, 50, who stated that "I think everyone should muck in. I think one in ten or even one in a dozen, you'd have more than enough marshals." Sarah had come to a similar conclusion:

I thought, 'Right, if I'm going to do this and they rely on volunteers, my thought would be that I'll volunteer once every ten runs,' is what my thought was ...That was my thought in my head, that that was would be a reasonable amount of volunteering. (Sarah, 45)

The participants who had volunteered at the point of completing the survey included two, Anita and Ian, who had run-directed, and Tom, who had begun parkrunning more recently but had already volunteered several times. Theirs were among the strongest views expressed regarding the need for all parkrunners to volunteer on occasion. Anita suggested the difficulty in recruiting volunteers was related to society more widely: 
I think helping other people or volunteering my time if I have the time, I wouldn't bat an eyelid at that. I don't mind going and standing in the park for an hour if the only other thing I have to do is sitting at home in front of the television. Both are equally relaxing; one of those is much better for the community. I think that feeling has been lost somehow within our society. (Anita, 30)

Ian, on the other hand, was critical of those who had run a large number of times without volunteering:

Where people who've run two hundred and fifty, three hundred times, and when you look down the list when you go on the site, you look down the list, there's quite a few of these people, and it's just a shame that I don't think they give anything back, because it's such a brilliant thing, and it's only through the volunteers and the event directors, et cetera, who set this all up and who are there for the runners, that these people who have done that amount of runs don't volunteer. (Ian, 69)

Anita and Ian both discussed recruitment difficulties that they sometimes experienced as core team members; they were not involved with the same parkrun (indeed, their events are a considerable distance from each other), suggesting this is not isolated or limited to a particular area. 
Tom actively suggests to other runners that they should be volunteering every tenth run, and that if they run without ever volunteering, they are not being fair.

Well, you pay tax on life in everything else. It really winds me up when you hear people whinging and politics about this, that and the other. I believe if you're taking something out, you've got to give something back in. For me, I look at it as a bit of a taxation. For my ten runs that I'm enjoying, I'm going to muck in and do one marshalling. I always tell people, and I tell people at the running club on Tuesday night, I said, 'Every tenth one.' I said, 'Yes you've got to do one in ten. You're taking the mickey. If you're expecting people to stand in the rain every Saturday so that you can enjoy your Saturdays ad infinitum, it's not fair. You've got to be fair and you've got to let other people have the chance.' No-one disagrees. (Tom, 50)

\section{Reluctance to miss a run}

Although participants were unanimous in their belief that they should volunteer from time to time and "give back" to parkrun, most (eight out of ten) expressed a preference for running/walking which conflicted with feeling obligated to volunteer. Sue summarised this:

It's a tough choice, because quite often I want to run to try and get myself better and get my number of runs up. So it's a hard one to get my head around. But I felt I ought to [volunteer]. (Sue, 45) 
Participants had identified roles where they could both volunteer and run, such as sorting finishing tokens after the event, or being the tail walker:

If you couldn't run and volunteer on the same day, I don't know what I'd be doing. That would be difficult for me because I so look forward to the run in order to try and improve my time or get a PB for the particular course, so I would feel a slight sense of loss if I had to miss my run. (John, 52)

There was, however, evidence of moral self-judgement that it was less altruistic to volunteer in a way that either allowed the individual to take part, or volunteer in weeks where they were unable to run. For example, Margaret, 58, described herself as "a little bit selfish. I went for tail runner because it meant I could still run" (Note: the tail runner role has recently been re-named as tail walker). Anita expressed a similar sentiment:

I suppose I'm guilty of it, but the first times I volunteered were always times where for some reason I couldn't run; either I'd injured myself or I had something else to go to straight afterwards so I didn't want to be all sweaty. (Anita, 30)

This was not widely evident in the data, however, despite the majority of parkrun volunteer roles precluding the volunteer from also running/walking that week.

Free tee-shirts are awarded for volunteering on 25 occasions, and 50, 100, 250 and 500 runs (for adults: juniors qualify for a 10 parkrun tee-shirt). Qualifying for a volunteering tee- 
shirt, despite being achievable in half the time of qualifying for a running tee shirt, was seen as much more challenging because of missing runs/walks:

I know there are people who volunteer most weeks, and it feels more like obviously that's something achievable for them, but not so much for me because I obviously want to prioritise running. I think if it was a bit smaller, ten or fifteen or something, I think that's within grasp enough that I would increase the number of volunteering sessions that I did, but whilst still being able to run as much as I like. (Lucy, 26)

It does because obviously you've got to potentially give up twenty-five runs to do that. Okay, there are roles you can do that include a run as well, but I think it's probably working out what those are, or maybe parkrun should maybe promote those roles more because they would probably get more volunteers if they realised what ones they could do, where they could run first and then do a volunteer role. (Margaret, 58)

Margaret's reference to "giving up" runs to volunteer, and the earlier comment from John about the "slight sense of loss" of not running, indicate that runners may perceive volunteering as missing out on running/walking, rather than contributing to providing that chance to others. There was evidence that, in addition to participants preferring to run/walk, the milestone running/walking tee-shirts may be disincentivising volunteering, with Lucy prioritising running milestones ahead of volunteering: 
It is difficult, because I would like to get to fifty, and because that seems to be a goal and you do realise that every time you don't run, that's one that's not adding to your fiftieth. (Lucy, 26)

Tom felt that the runs required an extrinsic motivator such as a tee-shirt, but that volunteering should not be recognised in the same way:

The tee-shirt for marshalling, I think is a stupid idea...I don't think that works in any way whatsoever...The tee-shirt for the running is brilliant...That extrinsic motivation works for the running, but I've talked to marshals, and I've never even seen anyone wearing the marshalling tee-shirt. (Tom, 50)

These comments suggest that milestone tee-shirts for running/walking are perceived differently by some people to those for volunteering. For Lucy, the volunteering input to receive one was felt to be too onerous and the tee-shirt was not incentivising, but she was motivated by the running/walking milestones. Tom felt the running/walking shirts were a positive, but the volunteering tee-shirt was "a stupid idea." He based this on his perception of others who volunteer, rather than referring to himself, perhaps undermining the sense of mutual aid despite having volunteered on several occasions previously. Running goals and running milestones were priorities for Tom and Lucy. While mutual aid is associated with strong subcultures and shared interests (Bishop \& Hoggett, 1986), at parkrun the subcultural focus on inclusive running and walking may be compromising desire to volunteer. 
Two participants did not reflect reluctance to miss a run/walk. Ben had not yet volunteered but described how he was looking forward to doing so; being unable to run/walk was not mentioned. Ian, 69 , had been involved with core teams for a number of years and enjoyed having a role organising and did not feel he needed to run, although he had done so a number of times. His reasoning was that 'I'm retired now, I can run any time. I don't actually need to do a parkrun...I like organising things.” For Ian, volunteering was therefore enjoyable because it offered the chance to organise, and that in itself was an attraction.

\section{Summary}

The three strongest themes identified in relation to volunteering behaviour are clearly interlinked, and furthermore present an element of conflict. As a first stage, parkrunners quickly become "hooked", and this exact word was used by a number of participants to describe their desire to attend parkrun as runners or walkers often as possible. Recognition of the need to volunteer due to reliance of the event on volunteers followed this, and was acknowledged as a reasonable expectation, with some criticism of parkrunners who did not volunteer. However, this conflicted with a desire to run/walk in order to beat times and achieve milestones. Strategies to avoid missing runs/walks included volunteering on days where running/walking was not practical, or undertaking volunteer roles that operated alongside taking part in the run. Some participants framed this approach as less altruistic, presenting additional moral conflict with the social reciprocity they endorsed. 


\section{Discussion}

The findings present three interconnected themes: "Hooked", "Obligation to give back" and "Reluctance to miss a run", found in eight, ten and eight transcripts respectively. "Hooked" appears to contradict the move towards more individualised sport, in that there may be a drive to run with others. However, there are other factors that drive the impetus to run every week: the opportunity to improve times (and, if a result is disappointing, to return and try again the following week), the incentive of achieving milestones and the reward of a milestone tee-shirt, and the rapid, detailed feedback. "Obligation to give back" is characterised by a clear realisation of obligation, with embarrassment or guilt described if this was not met. Rather than altruism, this appears to be driven by a conscious appraisal of balance of "give-and-take", and the attempt to quantify what is reasonable. Several participants mentioned volunteering every 10 runs, but this is an arbitrary figure. Additionally, there was an expectation that others should do likewise. The third theme, "Reluctance to miss a run," related to "Hooked" and the strong drivers to run rather than volunteer, and language used related to sacrifice, such as "giving up a run" or "a slight sense of loss if I had to miss my run". This led to a search for volunteer roles that allowed the volunteer to run too, even though most of the roles prevent running; there was an attempt to avoid guilt yet still run.

\section{Theoretical implications}

There are several different types of volunteering at parkrun. Core teams are perhaps most like those administrating in groups in Bishop and Hoggett's work (Bishop \& Hoggett, 1986); there is a regular commitment, and they fulfil a "by some of us, for all of us" role. Alongside the core 
team, most roles can be described as episodic, taken on in an ad hoc manner, but typically requiring between 90 minutes and 2 hours of commitment. A few roles, such as sorting out finish tokens or helping with setting up the event, could be described as microvolunteering as they require 30 minutes or less of input; they also allow a run alongside the volunteering role. The slant towards episodic and microvolunteering is consistent with the trend of individualised, short-term leisure volunteering (Harris et al., 2017).

The differences between roles reflect varied net cost (Handy et al., 2000) to parkrun volunteers: how much time is required, whether the volunteer can also take part in the event, and if so, is their pace curtailed, for example as a pacer or tail-walker (a token-sorter would be able to run as fast as they wished). While one might envisage roles where the volunteer cannot also run being perceived as more valuable, this was not evident among the participants. However, volunteering in weeks where the runner was injured or had other obligations - and therefore net cost was lower - was seen as less valuable, despite the overall benefit for the event being the same.

This raises questions regarding the perception of running as being preferable to volunteering. Participants referred to "giving up" a run to volunteer, clearly perceiving a cost. The run can still be done at any time, and the parkrun website allows manual recording of "Freedom Runs" where the parkrun course is completed in the individual's own time, although this does not count towards a milestone. While there may be some interplay of constraints such as time pressure and childcare (structural) and dislike of "missing" a run (intrapersonal), the tendency to run rather than volunteer may simply be preference, which Godbey et al. (2010) argue is not a constraint: "The point is each and every one of us can only have a limited set of 
preferred leisure activities. When we are interested in certain activities, we are disinterested (or less interested) in many other activities" (p.126). While leisure constraints theory is applicable to some of the underlying influences on volunteering behaviour, it does not seem to provide the "universal framework" (p.124) its authors hoped for.

Participants described wanting to improve their times, and John described the results email, which includes a range of statistics, as being an element of being 'hooked'. It is possible that in addition to exercise stimulating brain reward circuits (Heyman et al., 2012), the results email, which includes various personal statistics, also operates as a "reward", stimulating dopamine release and prolonging the parkrun experience through anticipation of receiving an official result later in the day along with associated statistics. This may confer prestige and also fulfils the impetus both to self-monitor, and monitor others through comparison (Veissière \& Stendel, 2018) - for example, position in the field, and in age and gender category. While volunteers receive a thankyou email after the event, this provides far more limited information.

The emphasis on milestones reflects a level of "gamification": "the use of play, games and game-inspired design to improve the human condition" (Nacke \& Deterding, 2017, p.450). Web technology developments in recent years have facilitated gamification of parkrun, such as milestone tee-shirts. There are additional challenges through a parkrun-specific Chrome extension (running-challenges.co.uk) where parkrunners are encouraged to complete parkruns away from their home parkrun, for example making words from the initial letters of different parkruns; the emphasis is on running, rather than volunteering. Apps such as Strava and FitBit encourage social comparison of exercise activities, potentially contributing to the desire to run. 
Although social exchange theory (SET) has been criticised for its over-simplicity (Emerson, 1976), there was evidence of a very conscious balancing of give-and-take among participants. They described feeling a clear sense of social obligation, alongside the need to quantify what was a reasonable balance to allow them to run as often as possible without feelings of guilt. Additionally, participants believed all parkrunners should volunteer, presenting a very obvious framework of social exchange. This might also be seen as extending the idea of mutual aid (Bishop \& Hoggett, 1986) - not just "by some of us for all of us", but a requirement that "all of us" should, from time to time, take the "some of us" roles.

The suggestion of volunteering once every ten runs attempts to standardise the expectation and commitment, but there were also individual differences affecting reciprocity, consistent with Freitag and Manatschal's work (2014). An altruism-egoism continuum (Hustinx et al., 2010) whereby different participants indicated different levels of propensity to "give back" was evident. For example, Anita felt she should be more altruistic and make a genuine sacrifice rather than coinciding volunteering with times she would not have been able to run, while John felt microvolunteering, where he could still run (unlike most of the other volunteers) was fulfilling his perceived obligations. Yet presenting parkrun volunteering as ranging from most to least altruistic, from core team work to microvolunteering, is to oversimplify. Ian's regular volunteering fulfilled a social need and he enjoyed being an organiser. The core team may have conferred a sense of belonging, and this is the less observable benefit of volunteering (Paraskevaidis \& Andriotis, 2017).

Biographical elements (Hustinx \& Lammertyn, 2003) influenced volunteering; children were mentioned as a barrier to both running and volunteering, while John mentioned that 
needing to car-share with the family meant all of them had to volunteer or wait around afterwards, which was seen as a barrier. Furthermore, informal contributions such as accompanying friends on their first parkrun, or encouraging other runners, are seen as altruistic activities (Stevinson \& Hickson, 2014) which may affect the perceived social exchange balance and lead to fewer occasions of formal volunteering.

Overall, parkrun offers ad hoc involvement both with volunteering and running, with lower levels of obligation than might be expected from joining some community groups. There is still a strong sense of identification and obligation nevertheless, probably facilitated in part by the subculture of parkrun language and milestone achievements. While this may increase a sense of belonging and hence propensity to volunteer, it may also have the counterproductive effect of strongly incentivising running ahead of volunteering.

\section{Limitations}

The study had a number of limitations. Attempts to recruit interviewees who had not volunteered were largely unsuccessful; all those who had not volunteered at the time of the survey and who agreed to an interview had since volunteered, except for one participant who had registered to volunteer in the few weeks following the interview (indeed, it is possible that the original survey triggered respondents to volunteer). To recruit 10 participants, 101 survey respondents who had expressed willingness to be contacted regarding interviews were emailed; most did not respond. This means some groups are underrepresented. However, there was not an aim to reach saturation, nor to ensure findings could be extrapolated; the intention was to collect richer and 
more detailed data than was possible with a survey, and to look for themes that might underpin the survey results.

\section{Future research}

The findings here show the difficulty of creating a balance between participation and administering an event where reciprocity is fundamental to the delivery model. The incentive to run regularly has great potential to enhance physical and mental health in communities, and parkrun is very successful at provision of a user-friendly event. Ensuring volunteer rosters are filled can be time-consuming for core teams, with last-minute uncertainty, so looking at ways to fill rosters more easily, well in advance of events, could help ensure sustainability and provide a model for other events. Future research could approach this firstly by more in-depth qualitative research with those who never volunteer despite having attended many times, and might also test interventions to encourage volunteering, such as promoting a "one in ten" level. The large number of events lends itself to cluster designs and facilitates opportunities to test control and intervention conditions.

\section{Positionality}

The researchers' involvement with parkrun over a number of years, running and volunteering, may have influenced interviews and findings due to lack of impartiality despite efforts to minimise this through limited disclosure to participants. RH is a frequent parkrunner, who first "parkran" in 2010 and has also volunteered regularly including as part of a core team, while Author 2 has also attended parkrun occasionally as a runner. Nevertheless, familiarity with 
parkrun enabled the researchers to explore the topics being discussed more effectively through raising issues and discussing aspects of parkrun that a less involved researcher may have been unaware of. The original impetus for the research was to understand better why parkrunners do or do not volunteer, with the intention of being able to apply findings to help volunteer recruitment.

\section{Conclusion}

This study presents insights into reciprocal volunteering behaviour at a community sport event, and the conflicts in motivation and purpose this involves. Participation, achieving milestone runs/walks, the need for volunteering for events to go ahead, and the recognition of necessary social exchange presented some difficulties in resolution among study participants. In turn, this led to volunteering strategies where certain roles were avoided so that both desire to run/walk and perceived obligation to volunteer could be fulfilled. This indicates the individualised levels of practicality and motivation, demonstrating the very varied circumstances of parkrunners. These findings add new elements of understanding reciprocity in volunteering, and may help develop ways of encouraging volunteering, increasing event sustainability and extending benefits for community health and wellbeing. 


\section{References}

Alfes, K., Antunes, B., \& Shantz, A. D. (2017). The management of volunteers - what can human resources do ? A review and research agenda. The International Journal of Human Resource Management, 28, 62-97. https://doi.org/10.1080/09585192.2016.1242508

Bishop, J., \& Hoggett, P. (1986). Organizing around enthusiasms: Mutual aid in leisure. London, UK: Comedia.

Braun, V., \& Clarke, V. (2006). Using thematic analysis in psychology. Qualitative Research in Psychology, 3, 77-101. https://doi.org/10.1191/1478088706qp063oa

Brudney, J. L., \& Meijs, L. C. P. M. (2009). It Ain't Natural: Toward a New (Natural) Resource Conceptualization for Volunteer Management. Nonprofit and Voluntary Sector Quarterly, 38, 564-581. https://doi.org/10.1177/0899764009333828

Crawford, D. W., \& Godbey, G. (1987). Reconceptualizing barriers to family leisure. Leisure Sciences, 9(2), 119-127. https://doi.org/10.1080/01490408709512151

Cunningham, C. (1996). Urban planning and philosophy: the concept of altruistic surplus. In G. G. van der Meulen \& P. A. Erkelens (Eds.), Urban habitat: the environment of tomorrow. Eindhoven: Eindhoven University of Technology. Retrieved from https://pure.tue.nl/ws/files/4410715/463512.pdf\#page=95

Cuskelly, G., Taylor, T., Hoye, R., \& Darcy, S. (2006). Volunteer management practices and volunteer retention: A human resource management approach. Sport Management Review, 9, 141-163. Retrieved from https://www.sciencedirect.com/science/article/pii/S1441352306700237

Dallimore, D. J., Davis, H., Eichsteller, M., \& Mann, R. (2018). Place, belonging and the determinants of volunteering. Voluntary Sector Review, 9, 21-38. https://doi.org/10.1332/204080518X15161941913849

Declerck, C. H., Boone, C., \& Emonds, G. (2013). When do people cooperate? The 
neuroeconomics of prosocial decision making. Brain and Cognition, 81, 95-117.

https://doi.org/10.1016/j.bandc.2012.09.009

Department for Culture Media and Sport. (2015). Sporting Future: A new strategy for an active nation. Department of Education and Skills. Retrieved from https://www.gov.uk/government/uploads/system/uploads/attachment_data/file/486622/Sport ing_Future_ACCESSIBLE.pdf

Emerson, R. M. (1976). Social Exchange Theory. Annual Review of Sociology, 2, 335-362. Retrieved from http://www.jstor.org/stable/2946096

Freitag, M., \& Manatschal, A. (2014). Reciprocity and volunteering. Rationality and Society, 26, 208-235. https://doi.org/10.1177/1043463114523715

Godbey, G., Crawford, D. W., \& Shen, X. S. (2010). Assessing hierarchical leisure constraints theory after two decades. Journal of Leisure Research, 42(1), 111-134. https://doi.org/10.1080/00222216.2010.11950197

Grunseit, A., Richards, J., \& Merom, D. (2017). Running on a high: Parkrun and personal wellbeing. BMC Public Health, 18, Article 59. https://doi.org/10.1186/s12889-017-4620-1

Hager, M. A., \& Brudney, J. L. (2011). Problems recruiting volunteers: Nature versus nurture. Nonprofit Management and Leadership, 22, 137-157. https://doi.org/10.1002/nml

Handy, F., Cnaan, R. A., Brudney, J. L., Ascoli, U., Meijs, L. C. M. P., \& Ranade, S. (2000). Public Perception of "Who is a Volunteer": An Examination of the Net-Cost Approach from a Cross-Cultural Perspective. Voluntas: International Journal of Voluntary and Nonprofit Organizations, 11(1), 45-65. https://doi.org/10.1023/a:1008903032393

Harris, S., Nichols, G., \& Taylor, M. (2017). Bowling even more alone: trends towards individual participation in sport. European Sport Management Quarterly, 17, 290-311. https://doi.org/10.1080/16184742.2017.1282971

Heyman, E., Gamelin, F. X., Goekint, M., Piscitelli, F., Roelands, B., Leclair, E., ... Meeusen, R. (2012). Intense exercise increases circulating endocannabinoid and BDNF levels in 
humans-Possible implications for reward and depression. Psychoneuroendocrinology, 37(6), 844-851. https://doi.org/10.1016/j.psyneuen.2011.09.017

Hindley, D. (2018). "More Than Just a Run in the Park": An Exploration of Parkrun as a Shared Leisure Space. Leisure Sciences, 0400, 1-21. https://doi.org/10.1080/01490400.2017.1410741

Hustinx, L., Cnaan, R. A., \& Handy, F. (2010). Navigating theories of volunteering: A hybrid map for a complex phenomenon. Journal for the Theory of Social Behaviour, 40, 410-434. https://doi.org/10.1111/j.1468-5914.2010.00439.x

Hustinx, L., \& Lammertyn, F. (2003). Collective and reflexive styles of volunteering : A sociological modernization perspective. Voluntas: International Journal of Voluntary and Nonprofit Organizations, 14, 167-187. Retrieved from https://core.ac.uk/download/pdf/34300956.pdf

Isen, A. M. (2001). An influence of positive affect on decision making in complex situations : Theoretical issues with practical implications. Journal of Consumer Psychology, 11, 75-85. Retrieved from https://blogs.ncvo.org.uk/wp-content/uploads/kristenstephenson/ncvo_guidance_giving_a_little_time_micro-volunteering.pdf

Jenkinson, C. E., Dickens, A. P., Jones, K., Thompson-Coon, J., Taylor, R. S., Rogers, M., ,.. Richards, S. H. (2013). Is volunteering a public health intervention? A systematic review and meta-analysis of the health and survival of volunteers. BMC Public Health, 13(Article 773). https://doi.org/10.1186/1471-2458-13-773

Nacke, L. E., \& Deterding, S. (2017). The maturing of gamification research. Computers in Human Behavior, 71, 450-454. https://doi.org/10.1016/j.chb.2016.11.062

National Council of Voluntary Organisations (NCVO). (n.d.). Giving a little time: A practical guide to exploring and developing the potential of micro-volunteering for your organisation. Retrieved from https://blogs.ncvo.org.uk/wp-content/uploads/kristenstephenson/ncvo_guidance_giving_a_little_time_micro-volunteering.pdf 
Nichols, G., Hogg, E., Knight, C., \& Storr, R. (2019). Approaches to promoting sports volunteering. Voluntary Sector Review, 10, 3-18. https://doi.org/10.1332/204080519X15478200125132

Nichols, G., Knight, C., Mirfin-Boukouris, H., Uri, C., Hogg, E., \& Storr, R. (2016). Motivations of sport volunteers in England: A review for Sport England. London. https://doi.org/10.1080/02614360500467735

Paraskevaidis, P., \& Andriotis, K. (2017). Altruism in tourism: Social Exchange Theory vs Altruistic Surplus Phenomenon in host volunteering. Annals of Tourism Research, 62, 2637. https://doi.org/10.1016/j.annals.2016.11.002

parkrun. (2019). parkrun website. Retrieved January 10, 2019, from www.parkrun.com

Shye, S. (2010). The motivation to volunteer: A systemic quality of life theory. Social Indicators Research, 98, 183-200. https://doi.org/10.1007/s11205-009-9545-3

Stevinson, C., \& Hickson, M. (2014). Exploring the public health potential of a mass community participation event. Journal of Public Health (Oxford, England), 36, 268-274. https://doi.org/10.1093/pubmed/fdt082

Stevinson, C., Wiltshire, G., \& Hickson, M. (2015). Facilitating participation in health-enhancing physical activity: A qualitative study of parkrun. International Journal of Behavioral Medicine, 22, 170-177. https://doi.org/10.1007/s12529-014-9431-5

Stukas, A. A., Hoye, R., Nicholson, M., Brown, K. M., \& Aisbett, L. (2016). Motivations to volunteer and their associations with volunteers' well-being. Nonprofit and Voluntary Sector Quarterly, 45(1), 112-132. https://doi.org/10.1177/0899764014561122

United Nations General Assembly. (2002). Resolution A/RES/56/38. United Nations. Retrieved from http://dag.un.org/bitstream/handle/11176/237258/A_RES_56_38EN.pdf? sequence=3\&isAllowed $=\mathrm{y}$

van den Berg, L., \& Cuskelly, G. (2016). Non-volunteerism of university sport students: A leisure constraints theory approach. South African Journal for Research in Sport, Physical 
Education and Recreation, 38(1), 167-177.

Van Willigen, M. (2000). Differential benefits of volunteering across the life course. The Journals of Gerontology Series B: Psychological Sciences and Social Sciences, 55, S308S318. https://doi.org/10.1093/geronb/55.5.S308

Veissière, S. P. L., \& Stendel, M. (2018). Hypernatural monitoring: A social rehearsal account of smartphone addiction. Frontiers in Psychology, 9(FEB), 1-10. https://doi.org/10.3389/fpsyg.2018.00141

Waitt, G. (2003). Social impacts of the Sydney Olympics. Annals of Tourism Research, 30(1), 194-215. https://doi.org/10.1016/S0160-7383(02)00050-6

Wiltshire, G., \& Stevinson, C. (2018). Exploring the role of social capital in community-based physical activity: qualitative insights from parkrun. Qualitative Research in Sport, Exercise and Health, 10, 47-62. https://doi.org/10.1080/2159676X.2017.1376347 


\section{APPENDIX A}

\section{Semi-structured Interview Schedule}

Before we start, I need to let you know that this conversation is being recorded. Are you $\mathrm{OK}$ to continue?

- [verbal confirmation from participant to be given before proceeding]

- [Confirm consent is given to participate in the research]

- [Confirm information sheet has been seen and whether there are any questions]

I'll start with some quite general questions about you, and then we'll move on to the specifics. If there's anything you want to mention that I haven't asked about, then let me know. The aim is to find out what's important to you.

- Could you tell me a little bit about yourself - age, what you do, where you live, that sort of thing?

○ Prompt: ask about each detail individually

- Can you tell me a bit about how you started parkrunning?

○ Prompt: ask about year, ask if they can remember first time

- Talk about responses on questionnaire:

○ For volunteers

- First time volunteering

- Roles they've done and how they've found them

- What they enjoy most

- Any bad experiences

○ For non-volunteers

- Talk about the reasons they gave

- As much as possible, let them do the talking with minimal prompts to avoid instilling any sense of guilt/being judged

- End of interview: is there anything that we haven't covered that you think is important? 